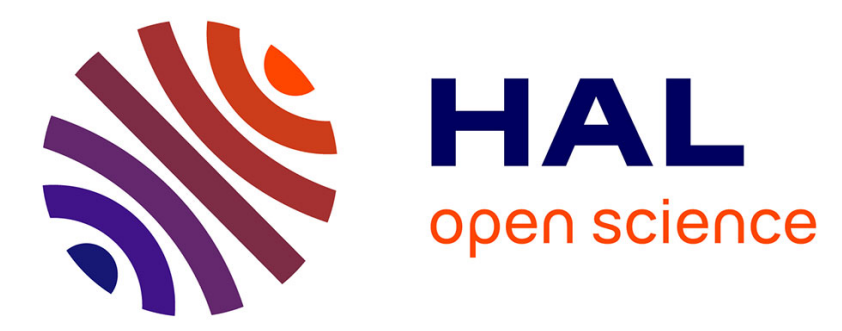

\title{
High-sorption terpyridine-graphene oxide hybrid for the efficient removal of heavy metal ions from wastewater
} Dawid Pakulski, Adam Gorczyński, Dawid Marcinkowski, Wlodzimierz Czepa, Tomasz Chudziak, Samanta Witomska, Yuta Nishina, Violetta Patroniak, Artur Ciesielski, Paolo Samorì

\section{- To cite this version:}

Dawid Pakulski, Adam Gorczyński, Dawid Marcinkowski, Wlodzimierz Czepa, Tomasz Chudziak, et al.. High-sorption terpyridine-graphene oxide hybrid for the efficient removal of heavy metal ions from wastewater. Nanoscale, 2021, 13 (23), pp.10490-10499. 10.1039/D1NR02255E . hal-03265092

\section{HAL Id: hal-03265092 https://hal.science/hal-03265092}

Submitted on 18 Jun 2021

HAL is a multi-disciplinary open access archive for the deposit and dissemination of scientific research documents, whether they are published or not. The documents may come from teaching and research institutions in France or abroad, or from public or private research centers.
L'archive ouverte pluridisciplinaire HAL, est destinée au dépôt et à la diffusion de documents scientifiques de niveau recherche, publiés ou non, émanant des établissements d'enseignement et de recherche français ou étrangers, des laboratoires publics ou privés. 


\title{
ARTICLE
}

\section{High-sorption terpyridine-graphene oxide hybrid for efficient removal of}

\section{heavy metal ions from wastewater}

Received 00th January 20xx, Accepted 00th January 20xx DOI: $10.1039 / \times 0 \times x 00000 x$

\author{
Dawid Pakulski, *a,b Adam Gorczyński, ${ }^{a}$ Dawid Marcinkowski, ${ }^{a}$ Włodzimierz Czepa, ${ }^{a}$ Tomasz

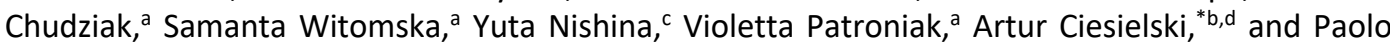 \\ Samorì ${ }^{* d}$
}

\begin{abstract}
Pollution of wastewater with heavy metal-ions represents one of the most severe environmental problems associated with the societal development. To overcome this issue, the design of new, highly efficient systems capable to remove such poisoning species, hence to purify water, is of paramount importance for public health and environmental protection. In this work, novel sorption hybrid materials were developed to enable high-performance adsorption of heavy metal ions. Towards this end, graphene oxide (GO) exhibiting various $\mathrm{C} / \mathrm{O}$ ratios has been functionalized with ad hoc receptors, i.e. terpyridine ligands. The maximum adsorption capacity of highly oxidized/terpyridine hybrids towards $\mathrm{Ni}(\mathrm{II}), \mathrm{Zn}$ (II) and Co(II) were achieved at $\mathrm{pH}=6$ and $25^{\circ} \mathrm{C}$ reaching values of 462,421 and $336 \mathrm{mg} \mathrm{g}^{-1}$, respectively, being the highest reported in the literature for pristine GO and GO-based sorbents. Moreover, the uptake experiments showed that the GO-Tpy as well as $\mathrm{GO}_{\mathrm{h}}$-Tpy adsorption of heavy metal ions is strongly dependent on the $\mathrm{pH}$ in the range from 2 to 10 , as a result of the modulation of interactions at the supramolecular level. Moreover, the ionic strength was found being independent of heavy metal ions adsorption on GO-Tpy and $\mathrm{GO}_{\mathrm{h}}$-Tpy. Under ambient conditions, adsorption capacity values increase with the degree of oxidation of GO because dipolar oxygen units can both interact with heavy-metal ions via dipole-dipole and/or ionic interactions and they enable higher amount of covalently-anchored terpyridine units. Both the adsorption isotherms and kinetics studies revealed that the uptake of the heavy metal ions occurs at a monolayer coverage, mostly controlled by the strong surface complexation with the oxygen of GO and terpyridine nitrogen-containing groups. Furthermore, selectivity of the hybrid was confirmed by selective sorption of the above heavy metal ions from mixtures involving alkali ( $\mathrm{Na}(\mathrm{I})$, $\mathrm{K}(\mathrm{I})$ ) and alkaline earth $(\mathrm{Mg}(\mathrm{II}), \mathrm{Ca}(\mathrm{II}))$ metal ions due to the chelating properties of the terpyridine subunits, as demonstrated on a municipal drinking (tap) water samples. Our findings provide unambiguous evidence for the potential of chemical tailoring of GO-based materials with N-heterocyclic ligands for highly efficient wastewater purification sorbent materials.
\end{abstract}

\section{Introduction}

One of the most detrimental downsides of the rapid industrial development is associated with its impact on the environment.1, 2 The increasing use of heavy metals for numerous applications in metallurgy, mining or chemical and battery manufacturing is highly relevant since it is the major source of the pollution of water reservoirs. ${ }^{3-5}$ This originates the bioaccumulation of heavy metal ions in the food chains, thereby compromising the ability to foster animal and plant life.6, 7 Their accumulation in

\footnotetext{
a. Faculty of Chemistry, Adam Mickiewicz University, Uniwersytetu Poznańskiego 8, 61-614 Poznań, Poland.

b. Center for Advanced Technologies Adam Mickiewicz University, Uniwersytetu Poznańskiego 10, 61-614 Poznań, Poland.

Research Core for Interdisciplinary Sciences, Okayama University, 3-1-1 Tsushimanaka, Kita-ku, Okayama, 700-8530, Japan.

d. Université de Strasbourg, CNRS, ISIS 8 allée Gaspard Monge, 67000 Strasbourg, France.

E-mail:dawid.pakulski@amu.edu.pl,ciesielski@unistra.fr,samori@unistra.fr + Electronic Supplementary Information (ESI) available: [details of any supplementary information available should be included here]. See DOI: $10.1039 / x 0 x x 00000 x$
}

human bodies results in the deterioration of the overall health, affecting all vital organs and eventually leading to chronic illnesses, overall lifespan shortening and, in worst-case scenario, premature death. ${ }^{8,9}$

The most economically viable and therefore industrially applied methods for wastewater treatment are based on the adsorption techniques, usually in the form of membranes employed in desalination or chemisorption setups. ${ }^{10-14}$ Over many years, researchers have explored the effectiveness of various adsorbents in these processes, including activated carbon (AC), zeolites, covalent organic frameworks (COFs), polymers, biosorbents, and other low-cost materials. ${ }^{15-27}$ However, practical application of these systems is limited due to low adsorption capacities, problematic separation and poor recyclability, yielding an overall limited effectiveness. As a result, tremendous effort has been made in recent years to design and develop new sorption materials towards enhanced sorption capacity; towards this end, graphene-based materials were shown to be the extremely effective for this application. ${ }^{28-}$ 31 For example, Seo and co-workers demonstrated the applicability of graphene-based membranes for desalination of 
water from Sydney Harbour. ${ }^{32}$ The unique properties of twodimensional materials (2DMs), and in particular their significant chemical stability and their high surface-to-volume ratio determined by their atomic thickness, render them particularly adaptive as adsorbents. Among 2DMs, graphene oxide (GO) can be produced in large scale and exposes on its surface various oxygen containing functional groups (e.g., epoxide, hydroxide and carbonyl) that can per se bind metal ions via the chelation mechanism and/or electrostatic interaction, and can be used as anchoring points for further chemical functionalizations. ${ }^{33-35}$ As a result, GO-based adsorbents are considered as attractive candidates for harvesting pollutants from aqueous solutions. In the last few years, several works have demonstrated the huge potential of GO and modified GO-based materials in sorption process towards different organic and inorganic pollutants, ${ }^{36}$ and revealed the impressive adsorption properties towards heavy metals ions (e.g., 138-180 $\mathrm{mg} \mathrm{g}^{-1} \mathrm{Ni}(\mathrm{II}),{ }^{37-39} 297-345 \mathrm{mg}$ g${ }_{1} \mathrm{Zn}(\mathrm{II}),{ }^{40,} 41$ 21-116 $\left.\mathrm{mg} \mathrm{g}^{-1} \mathrm{Co}(\mathrm{II})^{42,43}\right)$. Furthermore, it has been shown that the changes in the adsorption capacity and selectivity are strictly correlated with the chemical functionalization GO surface $37,38,40-43$ and degree of oxidation of graphene oxide. ${ }^{44,45}$ Unfortunately, there are still some limitations that, if solved, can make utilization of GO-based materials in the wastewater-derived adsorption processes a widely applied methodology. In particular, these materials are typically highly dispersible in water, therefore their regeneration and repeated utilization are not economically feasible. To overcome these drawbacks and towards a sustainable approach, an appropriate synthetic route needs to be devised to increase the degree of oxidation in GO. This implies the presence of a greater number of groups that can act as anchoring points for further functionalization, enabling the fine tuning of the material's properties. As a result, the inherent sorption properties would be expected to increase offering a major step forward compared to the current state-of-the art.

Among various supramolecular receptors of heavy-metal ions, $^{3,} 46$ multidentate organic ligands and in particular oligopyridines seem to be a perfect choice for enhancement of the sorption of GO-based materials due to their high complexation constants and sensitivity towards this type of analytes. ${ }^{47-50}$ In fact, the successful grafting of $\mathrm{N}$-heterocyclic ligands to GO materials was already demonstrated,51-55 however their utilization was limited to energy conversion processes and anticorrosive properties.

Here, we present a modular strategy towards the generation of a novel library of three-dimensional (3D) porous hybrids, constructed from 4-([2,2':6',2"'-terpyridin]-4'-yloxy)butan-1amine (Tpy) and GO with two different degrees of oxidation as presented on Fig. 1. We envisage that the introduction of the Tpy group could serve as an efficient metal-ion scavenger but would also impose in an increase the interlayer spacing between GO sheets, thus enhancing the specific surface area of the material. We have produced GO sheets with different amount of oxygen functionalities which yielded tunable degree of Tpy-functionalization of the GO. These functionalized GO were exploited to quantify the adsorption capacity and unravel the mechanism of $\mathrm{Ni}(\mathrm{II}), \mathrm{Zn}(\mathrm{II})$ and $\mathrm{Co}(\mathrm{II})$ sorption, allowing to achieve the highest reported values of the maximum adsorption capacity $\left(q_{\max }\right)$ within GO and GO-based sorbents (see table S1). Moreover, we demonstrated a high selectivity in the sorption of heavy metal ions from mixtures involving alkali $(\mathrm{Na}(\mathrm{I}), \mathrm{K}(\mathrm{I}))$ and alkaline earth $(\mathrm{Mg}(\mathrm{II}), \mathrm{Ca}(\mathrm{II}))$ metal ions. High stability and reusability of our sorbent materials was also proven, thus providing a very promising strategy towards the generation of novel and more performing sorbent materials for wastewater treatment.

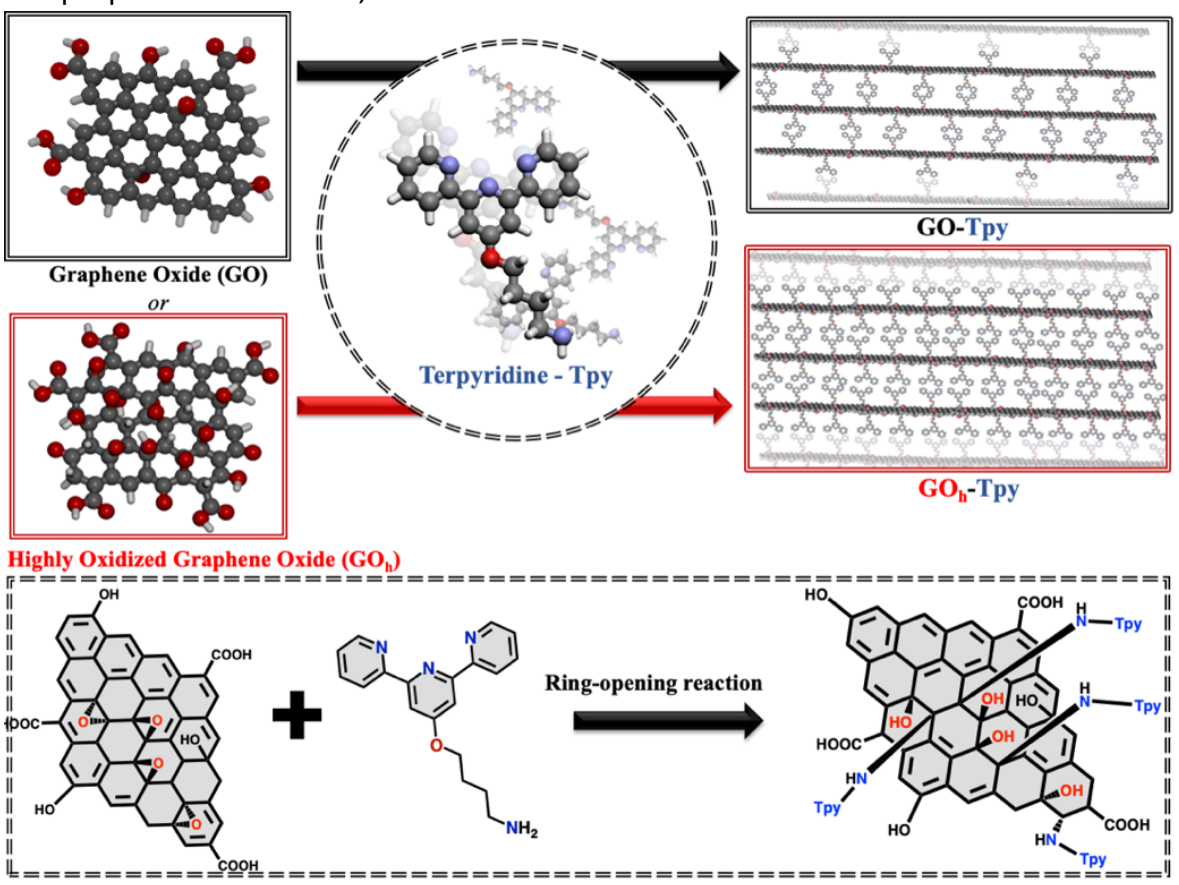

Fig. 1 Schematic representation of the functionalization of graphene oxide with two levels of oxidation ( $G O$ and $G O_{h}$ ) with $T p y$ using ring-opening reaction of epoxides yielding GO-Tpy and $\mathrm{GO}_{\mathrm{h}}$-Tpy. 


\section{Results and discussion}

\section{Synthesis and characterization of GO-Tpy and $\mathrm{GO}_{\mathrm{h}}$-Tpy hybrids}

A family of 3D porous GO-Tpy and $\mathrm{GO}_{\mathrm{h}}$-Tpy hybrids was produced by combining graphene oxides batches differing in the degree of oxidation $\left(\mathrm{GO}\right.$ and $\mathrm{GO}_{h}$ ) with tridentate terpyridine ligands (Tpy) (fig. S1) decorated with short amino-alkyl chain for covalent attachment to the GO materials. Overnight reflux, followed by filtration, Soxhlet extraction and freeze-drying allows one to obtain the final material in the pure form in maximum yield with respect to the graphenic system. Such an approach allows one to achieve an efficient decoration of 2D GO surfaces using the pendant amine group of the Tpy scaffold, while retaining the ability of the latter to coordinate heavy metal ions upon its integration into the hybrid material. Careful optimization allowed us to establish that two-fold excess of Tpy with respect to $\mathrm{GO} / \mathrm{GO}_{\mathrm{h}}$ is the optimum mass ratio to ensure full saturation of the $\mathrm{N}$-heterocyclic material into the carbonaceous matrix. Noteworthy, XPS analysis can provide semiquantitative information concerning the composition, ${ }^{56}$ which helped us to estimate the ratio between the number of carbon atoms of graphene oxide over the number of $\mathrm{N}$-heterocyclic moieties (see $\mathrm{SI}$ ). We calculated the degree of functionalization revealed that $\mathrm{GO}_{\mathrm{h}}-\mathrm{Tpy}$ possesses two times more Tpy subunits than GO-Tpy. In other words, the higher number of oxygen-containing moieties in $\mathrm{GO}_{h}$ when compared to GO allows more dense grafting of the Tpy moieties onto the material.

The GO, GOh, GO-Tpy and $\mathrm{GO}_{\mathrm{h}}$-Tpy were investigated by Raman spectroscopy which is a non-destructive and well-established technique used to determine the structure and interaction between components (Fig. S2). The Raman spectra of $\mathrm{GO}_{h}$ and $\mathrm{GO}_{h}$-Tpy display two characteristic bands which correspond to the $D\left(1340 \mathrm{~cm}^{-1}\right.$ for $\left.\mathrm{GO}_{\mathrm{h}}\right)$ and $\mathrm{G}\left(1593 \mathrm{~cm}^{-1}\right.$ for $\mathrm{GO}$ and $\mathrm{GO}_{\mathrm{h}} ; 1584 \mathrm{~cm}^{-1}$ for GO-Tpy and $\mathrm{GO}_{\mathrm{h}}$-Tpy) modes. The $\mathrm{G}$ band is observed in most of graphite-based materials and it is related to the $E_{2 G}$ vibrational mode of ordered inplane $\mathrm{sp}^{2}$ hybridized carbon bonds, whereas $\mathrm{D}$ band corresponds to the disorder of the edge carbons and is forbidden in an ideal graphite. Compared to $\mathrm{GO}$ and $\mathrm{GO}_{\mathrm{h}}$, the G-band of GO-Tpy and $\mathrm{GO}_{\mathrm{h}}$ Tpy appears at $1584 \mathrm{~cm}^{-1}$, being down shifted by $9 \mathrm{~cm}^{-1}$, thereby confirming the charge transfer between $\mathrm{GO}_{h}$ and Tpy units. This is consistent with the observations related to amino-functionalized graphene oxide hybrid, ${ }^{57}$ which shows a strong covalent interaction between both components. Typically, chemical modification of graphene-based materials is studied by the changes in the ratio of $D$ and $G$ bands intensities $\left(I_{D} / I_{G}\right) .^{58-60}$ When compared to pristine $G O$ $\left(I_{D} / I_{G}=0.95\right)$, the $I_{D} / I_{G}$ of GO-Tpy becomes higher $\left(I_{D} / I_{G}=1.07\right)$ and can be attributed to the increase of $\mathrm{sp}^{3}$ hybridized carbon atoms after functionalization (Fig. S2). Comparably, after functionalization of Tpy with highly oxidized $\mathrm{GO}_{h}$, the $\mathrm{I}_{\mathrm{D}} / \mathrm{I}_{\mathrm{G}}$ increased from 0.96 (for
$\mathrm{GO}_{h}$ ) to 1.13 for $\mathrm{GO}_{h}$-Tpy. Fourier transform infrared spectroscopy (FT-IR) further confirmed the covalent modification of $\mathrm{GO} / \mathrm{GO}_{\mathrm{h}}$ with the Tpy as shown in Fig. S3. Once the Tpy interacts with $\mathrm{GO}_{\mathrm{h}}$ a reaction between amine groups of Tpy with epoxy as well as carbonyl units located on the basal plane of $\mathrm{GO}_{\mathrm{h}}$ takes place. ${ }^{61}$ Since the strong $\mathrm{H}$-bonding coming from the $\mathrm{GO}_{\mathrm{h}}$ essentially overlaps with the characteristic features of the high-energy IR spectrum, changes below $1800 \mathrm{~cm}^{-1}$ are proof of successful Tpy functionalization. New bands at $1582 \mathrm{~cm}^{-1}\left(\mathrm{~N}-\mathrm{H}\right.$ bending vibration) and $784 \mathrm{~cm}^{-1}(\mathrm{~N}-\mathrm{H}$ outof-plane wagging mode) in GO-Tpy and $\mathrm{GO}_{\mathrm{h}}$-Tpy spectra demonstrated that the grafting occurred through the amino groups (red dashed lines on Fig. S3)) (also confirmed with XPS study presented below). Characteristic Tpy signals of the $\mathrm{sp}^{2}$ aromatic counterparts were also present in the final materials (blue dashed lines on Fig. S3), which further confirmed the successful covalent functionalization.

X-ray photoelectron spectroscopy (XPS) analysis was performed to further verify the chemical composition and electronic state of the resulting GO, $\mathrm{GO}_{\mathrm{h}}, \mathrm{GO}-\mathrm{Tpy}$ and $\mathrm{GO}_{\mathrm{h}}$-Tpy (Fig. S4-S5). The important distinction between the carbon (C1s) and nitrogen (N1s) peaks provides evidence for the creation of new chemical bonds between the oxygen containing groups on the surface of $\mathrm{GO}$ and amine groups from the Tpy moieties (Fig. S5a-j). Moreover, thanks to this analytical method, we could clearly observe differences in oxidation degree in the GOs used in our work. In particular, the survey spectrum of GOTpy and $\mathrm{GO}_{\mathrm{h}}$-Tpy in Fig. S4 show photoelectron lines at a binding energy at ca. 285, 398 and $532 \mathrm{eV}$ which can be attributed to C1s, N1s and O1s peaks, respectively. The C1s XPS spectrum of the neat $\mathrm{GO}_{\mathrm{h}}$ (Fig. S5c) shows typical peaks at $284.4 \mathrm{eV}$ (C-C), $286.8 \mathrm{eV}$ (C-O) and peak at $288.7 \mathrm{eV}(\mathrm{C}=\mathrm{O})$, simultaneously indicating highly oxidized GO structure (see Fig. S5. for further information). In particular, the C1s spectra of $\mathrm{GO}_{\mathrm{h}}$-Tpy exhibited the appearance of new prominent peak at $285.8 \mathrm{eV}$, which can be assigned to $\mathrm{C}-\mathrm{N}$ bonds. An increase in the intensity of the peak C-C $(284.4 \mathrm{eV})$ at $\mathrm{C} 1 \mathrm{~s}$ of $\mathrm{GO}_{\mathrm{h}}$-Tpy (Fig S5i) confirms the connection of $\mathrm{GO}$ with Tpy. Additionally, a significant decrease of peak attributed to $\mathrm{C}-\mathrm{O}$ on Fig. $\mathrm{S} 5 \mathrm{~g}$-i bonds implies the main functionalization route is the epoxide ring opening reaction. Noteworthy, the successful functionalization of GO with Tpy is proved by the N1s spectra (Fig. S5h). The high-resolution N1s spectra of $\mathrm{GO}$ and $\mathrm{GO}_{\mathrm{h}}$ samples do not show any nitrogen signal (Fig. S5b,d), whereas the $\mathrm{N} 1 \mathrm{~s}$ spectra of GO-Tpy and $\mathrm{GO}_{\mathrm{h}}$-Tpy can be deconvoluted into three peaks at $398.8 \mathrm{eV}, 399.5 \mathrm{eV}, 402.2 \mathrm{eV}$ which can be ascribed to $\mathrm{C}=\mathrm{N}, \mathrm{C}-\mathrm{NH}-\mathrm{C}$, and $\mathrm{NH}_{3}{ }^{+}$, respectively (Fig. S5h). ${ }^{62-}$ 64 The protonated amines $\left(\mathrm{NH}_{3}{ }^{+}\right)$can cooperate in the functionalization process by means of electrostatic interactions with deprotonated carboxylic subunits. Moreover, the amount of $\mathrm{N}-\mathrm{C}$ bonds increased due to reaction between $\mathrm{NH}_{2}$ groups observed on Tpy with epoxy-carbon atoms on surface of GOs. 
The morphology and structural features of the GO, GO $\mathrm{h}$ GO-Tpy and $\mathrm{GO}_{\mathrm{h}}$-Tpy hybrids were investigated by scanning electron microscopy (SEM). SEM images of $\mathrm{GO}$ and $\mathrm{GO}_{h}$ portrayed in Fig. 2a-b revealed a highly wrinkled structure which facilitates achieving excellent contact with analysed solution. After functionalization of $\mathrm{GO}$ and $\mathrm{GO}_{\mathrm{h}}$ with Tpy subunit the GO-Tpy and $\mathrm{GO}_{\mathrm{h}}$-Tpy hybrids possess a homogenous 3D porous network structure when compared to the pristine substrates (Fig. 2c-d).

The results of the BET analysis, which is regarded as an effective strategy for investigating the specific surface area of nanomaterials, ${ }^{65-68}$ are shown in Fig. 2e. The $\mathrm{N}_{2}$ adsorptiondesorption isotherms measurements at $77 \mathrm{~K}$ of as-prepared $\mathrm{GO}_{\mathrm{h}}-\mathrm{Tpy}$ exhibit typical IV-type isotherms, indicating the presence of mesopores with many slit holes with the average pore diameter calculated with the Barrett-Joyner-Haleda (BJH) model to be $10.4 \mathrm{~nm}$ (see table S4 and Fig. S6 in Supporting Information). The specific surface area of $\mathrm{GO}_{\mathrm{h}}$-Tpy amounts to $185 \mathrm{~m}^{2} \mathrm{~g}^{-1}$, which is ca. 8 times greater when compared with the specific surface area of the starting material $\left(\mathrm{GO}_{\mathrm{h}}-\mathrm{ca}\right.$. 28. $\left.\mathrm{m}^{2} \mathrm{~g}^{-1}\right)$, and demonstrates that the Tpy moieties attachment yields an increase in the specific surface area of a)

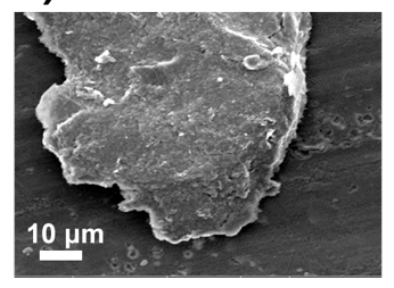

b)

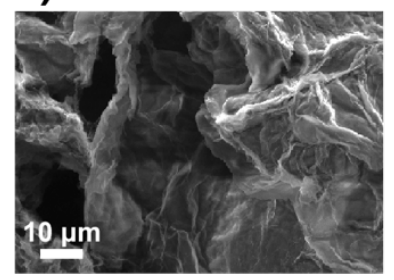

$\mathrm{GO}_{\mathrm{h}}$. Similar trends were observed for the GO-Tpy hybrid, nonetheless as a result of the lower degree of oxidation of $\mathrm{GO}$, the final specific surface area and average pore diameter decreased of ca. $80 \%$ and $85 \%$ values when compared to $\mathrm{GO}_{\mathrm{h}}$-Tpy system (table S4).

Structural characteristics of the hybrids as well as raw materials were studied by powder X-ray diffraction which is presented on Fig. $2 \mathrm{f}$. The starting materials $\left(\mathrm{GO}, \mathrm{GO}_{\mathrm{h}}\right)$ possess a typical sharp peak at $10.02^{\circ}$ corresponding to an interlayer spacing of $0.88 \mathrm{~nm}$ due to the 001 reflection of stacked $\mathrm{GO}$ sheets. The pristine $\mathrm{GO}$ sample possesses two peaks reflected at $2 \Theta=25.94^{\circ}$ and $10.02^{\circ}$, corresponding to the ordered (002) hexagonal graphitic planes and (001) defected hexagonal graphitic structure. The increase of oxidation degree results in the disappearance of the peak located at $25.94^{\circ}$, which proves that a large number of oxygen-containing groups have been introduced to the GO sheet. After functionalization process, the inter-layer spacing based on the Bragg equation increased from 0.88 to $1.09 \mathrm{~nm}$, indicating successful introduction of Tpy moieties between the $\mathrm{GO}$ sheets. c)

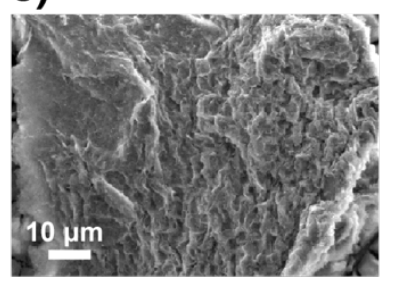

d)

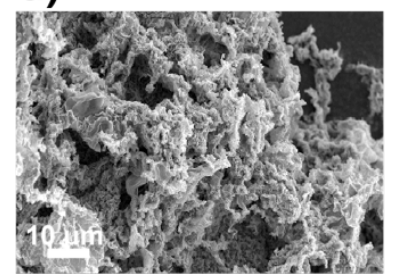

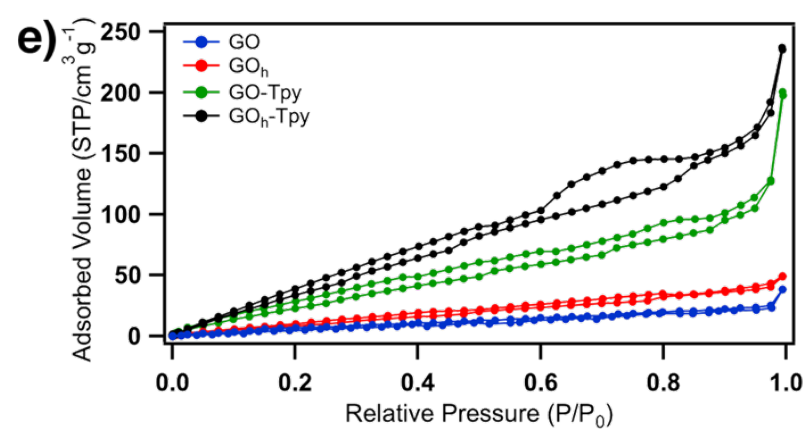

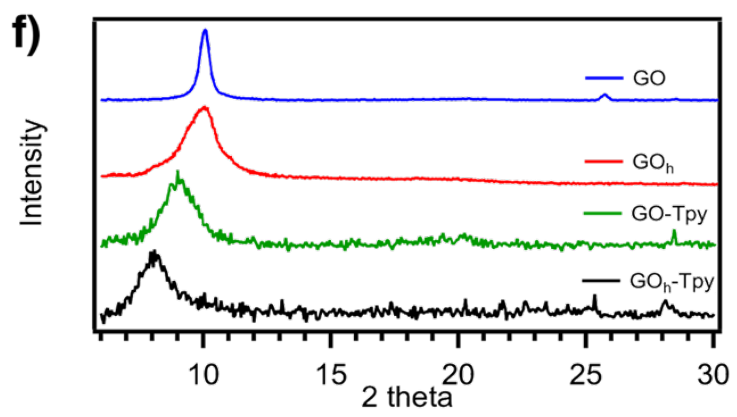

Fig. 2 SEM images displaying the morphology of a) GO, b) $\mathrm{GO}_{\mathrm{h}} \mathrm{c}$ ) GO-Tpy and d) $\mathrm{GO}_{\mathrm{h}}$-Tpy materials; e) BET adsorption-desorption isotherms of the $\mathrm{GO}, \mathrm{GO}_{\mathrm{h}}$, GO-Tpy and $\mathrm{GO}_{\mathrm{h}}$-Tpy hybrids; f) Wide-angle X-ray scattering patterns of $\mathrm{GO}, \mathrm{GO}_{\mathrm{h}} \mathrm{GO}$-Tpy and $\mathrm{GO}_{\mathrm{h}}$-Tpy powders.

The thermal stability of $\mathrm{GO}, \mathrm{GO}_{\mathrm{h}}, \mathrm{Tpy}, \mathrm{GO}-\mathrm{Tpy}$ and $\mathrm{GO}_{\mathrm{h}}-\mathrm{Tpy}$ (Fig. S7) was investigated using thermal gravimetric analysis (TGA). The $\mathrm{GO}_{\mathrm{h}}$ undergoes a significant weight loss of $c a .50 \%$ in range of $90-300^{\circ} \mathrm{C}$, indicating the decomposition of oxygen functional groups. ${ }^{69} \mathrm{Tpy}$ is thermally stable up to its melting point of ca. $230^{\circ} \mathrm{C}$ and its decomposition ends at $375^{\circ} \mathrm{C}$. Notably, $\mathrm{GO}_{\mathrm{h}}-\mathrm{Tpy}$ thermal decomposition was found to occur in two steps. First about $90^{\circ} \mathrm{C}$ indicating the removal of water which amount ca. $8 \%$ weight loss. Higher drop of mass percentage was monitored around $300^{\circ} \mathrm{C}$ and it can be associated with the deoxygenation process and Tpy thermal degradation. The results of TGA analysis for $\mathrm{GO}_{\mathrm{h}}$-Tpy hybrid indicate that functionalization of GO with Tpy group is characterized by an increase of the overall thermal stability of the hybrid material, which is a result of the replacement of the less-stable oxygen containing groups at the surface of $\mathrm{GO}_{\mathrm{h}}$ with the amine groups coming from Tpy. ${ }^{41}$

\section{Adsorption of metal ions on $\mathrm{GO}_{\mathrm{h}}-\mathrm{Tpy}$}

To determine the best conditions for the maximum removal of $\mathrm{Ni}(\mathrm{II})$, $\mathrm{Zn}(\mathrm{II}), \mathrm{Co}(\mathrm{II})$ ions from aqueous solutions, various adsorption parameters were changed systematically such as $\mathrm{pH}$, the contact time and heavy metal ions concentration. While it is notorious that the $\mathrm{pH}$ strongly affects the sorption of heavy metals because it influences the metal species and the charge generated on the adsorbent surface, in our specific case, this susceptibility is even more severe. In fact, the chemistry of our sorbent components, i.e. the modified graphene oxide $\mathrm{GO}_{\mathrm{h}}$ surface and the grafted Tpy subunit, is particularly sensitive to changes in $\mathrm{pH}$ since the scaffold's protonation can markedly modify association constants of their interaction with ions. This mostly affects the oligopyridine scaffold, where the equilibrium between the $\mathrm{H}^{+}$cation and heavy metal ions occurs. ${ }^{70}$ The effect of $\mathrm{pH}$ on the adsorption of $\mathrm{Ni}(\mathrm{II}), \mathrm{Zn}(\mathrm{II}), \mathrm{Co}(\mathrm{II})$, 
onto $\mathrm{GO}_{\mathrm{h}}$-Tpy was plotted in Fig. $\mathrm{S} 8$, with the $\mathrm{pH}$ values adjusted in the range from 2 to 10 . The adsorpion capacity of $\mathrm{Ni}(\mathrm{II}), \mathrm{Zn}(\mathrm{II})$ and $\mathrm{Co}$ (II) onto $\mathrm{GO}_{\mathrm{h}}$-Tpy was studied separately for each metal ion and increased quickly in $\mathrm{pH}$ range 2-6 to reach the maximum values at $\mathrm{pH}$ 6-7, which remained constant and slightly decreased from $\mathrm{pH} 7$ until $\mathrm{pH} 10$ (by ca. 10\%). At lower $\mathrm{pH}$, the relatively high $\mathrm{H}^{+}$concentration would strongly compete with metal ions for the adsorption sites due to protonation of the hydroxyl and carboxyl groups from the $\mathrm{GO}_{\mathrm{h}}$ surface ${ }^{71}$ as well as the Tpy subunit itself. ${ }^{72}$ This finds reflection in the determination of the $\mathrm{pH}$ point of zero charge $\left(\mathrm{pH}_{\mathrm{pzc}}\right)$, which is related to the surface charge properties of the adsorbent. ${ }^{73}$ Changes in zeta potential as the function of $\mathrm{pH}$ (Fig. S8) show that the $\mathrm{pH}_{\mathrm{pzc}}$ of the $\mathrm{GO}_{\mathrm{h}}$-Tpy is 4 , thus, the deprotonated surface of $\mathrm{GO}_{\mathrm{h}}$-Tpy, favors the adsorption of cationic species when the $\mathrm{pH}$ higher than 4 . Moreover, the as-prepared $\mathrm{GO}_{\mathrm{h}}$-Tpy is negatively charged in most of natural water environment, hence it is prone to form stable complex compounds with positively charged metal ions interacting with its surfaces. ${ }^{61}$ The slight decrease of adsorption of $\mathrm{Ni}(\mathrm{II}), \mathrm{Zn}$ (II) and $\mathrm{Co}$ (II) at $\mathrm{pH}$ 8-10 can be explained by the formation of hydroxide complexes e.g. $\mathrm{NiOH}^{+}, \mathrm{ZnOH}^{+}, \mathrm{CoOH}^{+}$(Fig. S9).

Specifically, the unique character of the hybrid material stems from the fact that the sole terpyridine ligands are prone to salting out of the solution in neutral aqueous environment, 72 whereas the GO materials can undergo $\mathrm{pH}$ dependent aggregation and/or micellization. ${ }^{71}$ Herein, neither of this happens and potent heavy metal ion chemisorption is observed via negatively charged carboxylic acid and hydroxyl groups, followed by the $\mathrm{N}$-heterocyclic Tpy moiety. High logK values of Tpy ligand towards heavy metal ions and weak-to-moderate towards alkaline and alkali metal ions also allows a selective binding of the former ones from tap water vs alkali and alkaline cations (vide infra). ${ }^{70,} 74$ In order to obtain high adsorption capacity and to prevent precipitation of the metals in the form of hydroxides which is observed for $\mathrm{Ni}(\mathrm{II}), \mathrm{Zn}(\mathrm{II}), \mathrm{Co}(\mathrm{II})$ at $\mathrm{pH}>7$ (Fig. S9), further experiments were carried out at $\mathrm{pH}=6$.

\section{Adsorption isotherms}

The Langmuir (Eq.3 in experimental section) and Freundlich (Eq.4) adsorption isotherms were used to investigate the maximum adsorption capacity $\left(q_{\max }\right)$ and to understand the adsorption mechanism of the chosen heavy metal ions (Ni(II), $\mathrm{Zn}(\mathrm{II}), \mathrm{Co}(\mathrm{II})$ ) on $\mathrm{GO}_{\mathrm{h}}$-Tpy. For the sake of comparison, control experiments including neat $\mathrm{GO}, \mathrm{GO}_{\mathrm{h}}$ and GO-Tpy as adsorbents were also carried out and presented on Fig. 3. Isotherm parameters obtained by fitting the Langmuir and Freundlich models are summarized in table S5. Noteworthy, the adsorption isotherms are better fitted by the Langmuir model than by the Freundlich model, suggesting that heavy metal ions adsorption onto the $\mathrm{GO}, \mathrm{GO}_{\mathrm{h}}, \mathrm{GO}$-Tpy and $\mathrm{GO}_{\mathrm{h}}$-Tpy are adsorbed with homogeneous binding sites, no interaction between adsorbed species, equivalent adsorption energies and monolayer coverage. Furthermore, the $n$ constant parameter obtained from Freundlich model is lower than 10 , indicating that the sorption process is favourable under studied conditions. ${ }^{75}$ Additionally, the XPS measurements were performed for $\mathrm{GO}_{\mathrm{h}}$-Tpy before and after adsorption of $\mathrm{Ni}(\mathrm{II}), \mathrm{Zn}(\mathrm{II})$ and $\mathrm{Co}(\mathrm{II})$ metal ions (Fig. S10), which confirm the strong surface complexation between adsorbent and metal species. The $q_{\max }$ values of $\mathrm{Ni}(\mathrm{II}), \mathrm{Zn}(\mathrm{II}), \mathrm{Co}(\mathrm{II})$ on $\mathrm{GO}_{\mathrm{h}}$-Tpy (see table S5) amount to 462,421 and $336 \mathrm{mg} \mathrm{g}^{-1}$, respectively, being larger than any known sorbents including GO and GO-based sorbents (see table S1). The $q_{\max }$ values expressed in $\mathrm{mmol} \mathrm{g}^{-1}$ amount to 7.9, 6.4 and 5.7 for $\mathrm{Ni}(\mathrm{II}), \mathrm{Zn}(\mathrm{II})$ and $\mathrm{Co}(\mathrm{II})$ respectively, suggesting that $1 \mathrm{~g}$ of $\mathrm{GO}_{\mathrm{h}}-\mathrm{Tpy}$ is able to adsorb ca. 6 to $8 \mathrm{mmol}$ of divalent heavy metal ions.
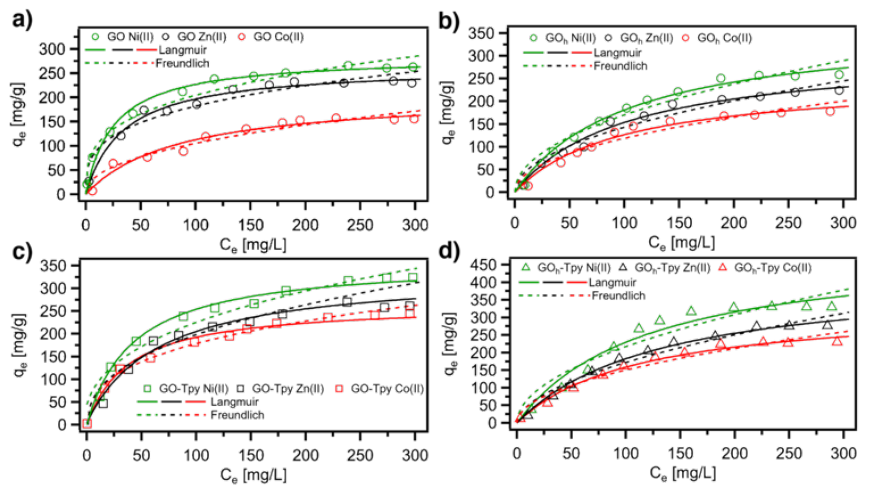

Fig. 3 Adsorption of heavy metal ions as a function of $\mathrm{Ni}(\mathrm{II}), \mathrm{Zn}(\mathrm{II})$, Co(II) concentrations. Uptake isotherms on control samples: a) raw $\mathrm{GO}, \mathrm{b})$ highly oxidized $\mathrm{GO}_{\mathrm{h}}, \mathrm{c}$ ) graphene oxide functionalized with terpyridine moieties (GO-Tpy), d) highly oxidized graphene oxide cross linked with terpyridine moieties $\left(\mathrm{GO}_{\mathrm{h}}-\mathrm{Tpy}\right)$. The uptake experiments were carried out at $\mathrm{pH}=6,\left(\mathrm{C}_{\mathrm{GO}, \mathrm{GOh}, \mathrm{GO}-\mathrm{Tpy}, \mathrm{GOh}-\mathrm{Tpy}}=0.2 \mathrm{~g} \mathrm{~L}-\right.$ $1, \mathrm{~T}=298 \mathrm{~K}$, stirring speed $=200 \mathrm{rpm}, \mathrm{t}=8 \mathrm{~h}$ ).

The affinity order of metal ions to the $\mathrm{GO}_{\mathrm{h}}$ and $\mathrm{GO}_{\mathrm{h}}$-Tpy hybrid were confirmed by the competitive adsorption using binary and tertiary mixtures $(\mathrm{Ni}(\mathrm{II}) / \mathrm{Zn}(\mathrm{II}) ; \quad \mathrm{Zn}(\mathrm{II}) / \mathrm{Co}(\mathrm{II}) ; \quad \mathrm{Ni}(\mathrm{II}) / \mathrm{Co}(\mathrm{II}) \quad$ and $\mathrm{Ni}(I I) / \mathrm{Zn}(\mathrm{II}) / \mathrm{Co}(\mathrm{II}))$ (Fig. 4a-b), which contained the metal ions solution at $\mathrm{pH}$ 6. Notably, the adsorption of $\mathrm{Ni}(\mathrm{II})$ was found being the highest in the presence of $\mathrm{Zn}(\mathrm{II})$ and $\mathrm{Co}(\mathrm{II})$ ions. The experimental data describing affinities of the metal ions toward the $\mathrm{GO}_{h}$-Tpy follow the order of $\mathrm{Ni}>\mathrm{Zn}>\mathrm{Co}$. This order agrees very well with first stability constant of the associated metal hydroxides and acetates according to table S6. Moreover, among the studied metal ions, Ni(II) displays the smallest value of ionic radius, facilitating its access in the adsorbents active sites, manifested by the greatest adsorption capacity value. The Tpy logK stability constants follows the following trend: $\mathrm{Ni}>\mathrm{Co}>\mathrm{Zn}$, which also explains the highest binding of the $\mathrm{Ni}(\mathrm{II})$ ions. ${ }^{72}$

lonic strength can considerably influence the adsorption process of metal ions due to the fact that the number of active functional groups is reduced because of the adsorption of other metal ions. Thus, we have studied the influence of $\mathrm{Ni}(\mathrm{II}), \mathrm{Zn}$ (II) and $\mathrm{Co}(\mathrm{II})$ adsorption on $\mathrm{GO}_{h}$ and $\mathrm{GO}_{h}$-Tpy in the solution of $\mathrm{NaNO}_{3}$ at different concentrations. As shown in fig.S11, even high concentration of background electrolyte $\left(1 \mathrm{~mol} \mathrm{~L}^{-1}\right)$ does not influence the adsorption of metal ions ( $\mathrm{Ni}(\mathrm{II}), \mathrm{Zn}(\mathrm{II}), \mathrm{Co}(\mathrm{II}))$. Moreover, the Tpy ligands alone precipitate under such condition, ${ }^{72}$ which is not the case when they are covalently bound to the graphene oxide matrix.

For the practical application in water remediation, the adsorbent should possess excellent regeneration and recycling performance and should function in the presence of interfering I and II group cations. Real-life application of the $\mathrm{GO}_{h}$ and hybrid $\mathrm{GO}_{\mathrm{h}}$-Tpy sorbent was demonstrated on purification of the drinking (tap) water, which contains alkali $(\mathrm{Na}(\mathrm{I}), \mathrm{K}(\mathrm{I}))$ and alkaline $(\mathrm{Mg}(\mathrm{II}), \mathrm{Ca}(\mathrm{II}))$ metal ions at the following concentrations: $16 \mathrm{mg} \mathrm{L}^{-1}, 7 \mathrm{mg} \mathrm{L}^{-1} 10 \mathrm{mg} \mathrm{L}^{-1}$ and $75 \mathrm{mg}$ 
$\mathrm{L}^{-1}$, respectively. Not only we observed that the single adsorption tests carried out for $\mathrm{Ni}(\mathrm{II}), \mathrm{Zn}(\mathrm{II}), \mathrm{Co}(\mathrm{II})$ metal ions in the presence of tap water are nearly identical to those obtained for MiliQ water experiments (Fig. 4c-d), but also successful regeneration of the material was demonstrated.

The ability of $\mathrm{GO}_{\mathrm{h}}$ and $\mathrm{GO}_{\mathrm{h}}$-Tpy regeneration was evaluated through a series of adsorption-desorption cycles. For each cycle, the hybrid is immersed in the aqueous solution of metal ions at $\mathrm{pH} 6$ and treated with $0.1 \mathrm{M} \mathrm{HNO}_{3}$. As presented in Fig. 4e-f, the overall decrease in adsorption capacity after ten cycles amounts to $90 \%$ ( $\mathrm{Ni}(\mathrm{II}), \mathrm{Co}(\mathrm{II}))$ or 95\% (Zn(II)) of the initial adsorption capacity, thus providing evidence that $\mathrm{GO}_{\mathrm{h}}$-Tpy hybrid is stable under the experimental process and shows excellent reusability even in comparison with pristine $\mathrm{GO}_{\mathrm{h}}$. The observed behaviour is a result of the choice of the $\mathrm{N}$-heterocyclic terpyridine moiety grafted onto the GO scaffold, which is synergically responsible for the dimensionalization of the system (higher stability and porosity) but also exhibits a few orders of magnitude higher complexes stability constant ( $\operatorname{logK}$ ) towards d-block metal ions vs. alkali and alkaline cations (selectivity). ${ }^{72}$ a)
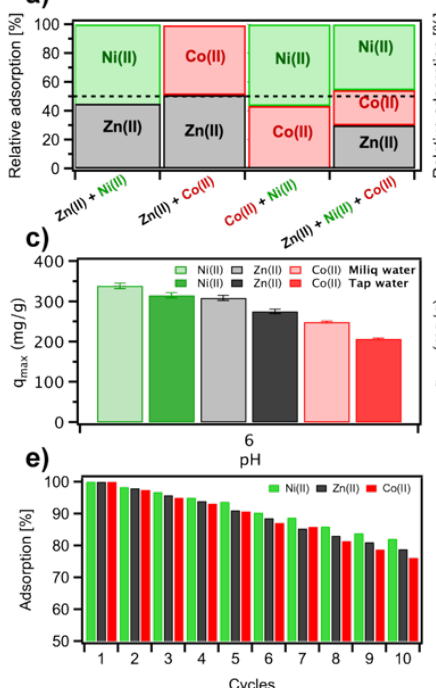

b)

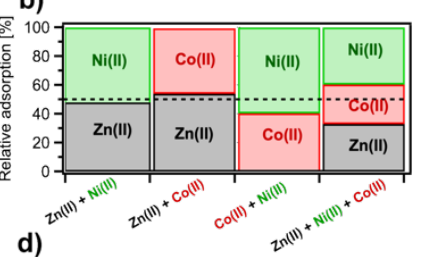

d)

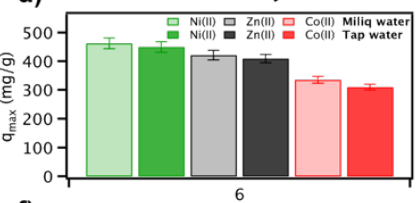

f)

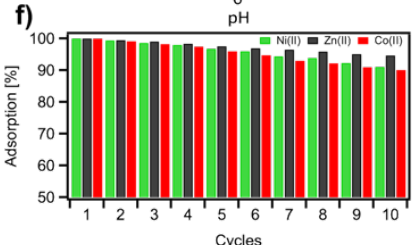

Fig. 4 Multicomponent (binary and ternary) sorption of $\mathrm{Ni}(\mathrm{II}), \mathrm{Zn}(\mathrm{II})$, $\mathrm{Co}(\mathrm{II})$ on a) $\mathrm{GO}_{\mathrm{h}}$ and b) $\mathrm{GO}_{\mathrm{h}}$-Tpy expressed as a percentage adsorption capacity. The effect of environmental conditions on the adsorption $\mathrm{Ni}(\mathrm{II}), \mathrm{Zn}(\mathrm{II})$ and $\mathrm{Co}(\mathrm{II})$ ions by c) $\mathrm{GO}_{\mathrm{h}}$ and d) $\mathrm{GO}_{\mathrm{h}}$-Tpy hybrids. Reusability studies of e) $\mathrm{GO}_{h}$ and f) $\mathrm{GO}_{h}$-Tpy after 10 cycles.

\section{Adsorption kinetics}

Since upon functionalization the highly oxidized $\mathrm{GO}_{\mathrm{h}}$ incorporates more coordinating Tpy moieties than the $\mathrm{GO}$, the $\mathrm{GO}_{\mathrm{h}}$-Tpy hybrid was chosen for subsequent metal-ion adsorption kinetic and thermodynamic studies. The effect of contact time on the adsorption of $\mathrm{Ni}(\mathrm{II}), \mathrm{Zn}(\mathrm{II})$ and $\mathrm{Co}(\mathrm{II})$ ions was investigated and portrayed in Fig. S12a. Compared with GO, where the metal adsorbs after ca. 20 min on its surface, ${ }^{40}$ the adsorption of heavy metal ions on $\mathrm{GO}_{\mathrm{h}}$-Tpy increases remarkably at the beginning of the experiment and then it reaches a plateau after $180 \mathrm{~min}$, whereas the maximum adsorption capacity is few times higher in comparison to pure GO. The adsorption rate is higher at the beginning due to the fact that greater number of reaction sites is available. According to the above results, the mixing time was fixed at $8 \mathrm{~h}$ in the following experiments to make sure that the adsorption reaction can achieve complete equilibrium. To identify the rate-controlling mechanisms during the adsorption of $\mathrm{Ni}(\mathrm{II}), \mathrm{Zn}(\mathrm{II})$ and $\mathrm{Co}(\mathrm{II})$, the pseudo-first-order (Fig. S12b), pseudosecond-order (Fig. S12c) and intra-particle diffusion model (Fig. S12d) were applied to estimate the experimental data. The calculated kinetic parameters for adsorption of $\mathrm{Ni}(\mathrm{II}), \mathrm{Zn}(\mathrm{II}), \mathrm{Co}(\mathrm{II})$ ions at $\mathrm{pH}=6$ are presented in table S7. The percentage adsorption reached 9597\% after $180 \mathrm{~min}$ for $\mathrm{Ni}(\mathrm{II}), \mathrm{Zn}(\mathrm{II}), \mathrm{Co}(\mathrm{II})$. The values of the correlation coefficient as well as the experimental adsorption values (qe) determined the applicability of the pseudo-second-order model for describing the experimental data, indicating that the adsorption process is driven by strong complexation of metal ions with the oxygen and nitrogen atoms of $\mathrm{GO}_{\mathrm{h}}$-Tpy (see table S7).

To gain insight into the adsorption process and analyze the ratedetermining step of the surface sorption reaction, the intra-particle diffusion model was applied. According to the model, if intraparticle diffusion is the rate limiting step of the entire adsorption process, the plots of $\mathrm{q}_{\mathrm{t}} v s \mathrm{t}^{1 / 2}$ should yield a straight line passing through the origin of the plot. ${ }^{76}$ Fig. S12d shows that the data points are related by two straights lines, the first sharper portion is attributed to the diffusion of adsorbate through the solution to the external surface of the adsorbent (external diffusion) while the second portion describes the gradual adsorption stage, corresponding to the diffusion of adsorbate molecules inside the adsorbent (intra-particle diffusion). ${ }^{77}$ The values of $k_{p 1}, k_{p 2}, C_{1}$ and $C_{2}$ calculated from the intercept and slope of plot $q_{t} v s t^{1 / 2}$ are summarized in table $S 8$. The intra-particle diffusion rate constant $\left(k_{p 1}\right)$ for the first sharper portion is higher than that $\left(k_{p 2}\right)$ for the second portion, whereas $C_{1}$ is lower than $C_{2}$, which shows that the rate of $\mathrm{Ni}(\mathrm{II}), \mathrm{Zn}(\mathrm{II})$ and $\mathrm{Co}(\mathrm{II})$ removal were higher at the beginning due to large surface area of the adsorbent available for the adsorption of metal ions. After the adsorbent gradually attained equilibrium, the capacity of adsorbent was controlled by the intra-particle diffusion. None of the plots passed through the origin, which indicates that the intra-particle diffusion was part of the adsorption but was not the only rate-controling step. ${ }^{78}$ Specifically, binding of cations to the Tpy subunits can happen either in the 1:1 'open' or 2:1 'closed' (Tpy:Me(II)) ratio, while the latter would result in an additional GO matrix folding. Few other mechanisms such as complexation or ion-exchange mechanism may also control the rate of adsorption process. ${ }^{79}$

\section{Adsorption thermodynamics}

To further investigate the nature of adsorption process, the thermodynamic behaviour has been studied by comparing the adsorption properties of the $\mathrm{GO}_{\mathrm{h}}$-Tpy at different temperatures. Determination of different thermodynamic parameters, including the Gibbs free energy $(\Delta G)$, the entropy $(\Delta S)$ and enthalpy $(\Delta H)$ changes, was done according to previously presented equations (see Eq. 8-9). The values of $\Delta \mathrm{H}^{\circ}$ and $\Delta \mathrm{S}^{\circ}$ can be determined from the slope and intercept by plotting the values of $\operatorname{InK}_{\mathrm{c}}$ vs. $1 / \mathrm{T}$ (Fig. S13). The obtained $\Delta \mathrm{G}, \Delta \mathrm{S}$ and $\Delta \mathrm{H}$ for the adsorption of $\mathrm{Zn}(\mathrm{II}), \mathrm{Co}(\mathrm{II})$ and $\mathrm{Ni}(\mathrm{II})$ ions on the $\mathrm{GO}_{\mathrm{h}}$-Tpy are listed in table S9. The negative values of $\Delta \mathrm{G}^{\circ}$ at different temperatures (298-318 K) confirmed the spontaneous nature of the adsorption process. The decreasing $\Delta G^{\circ}$ values with the increasing temperature provide evidence that sorption process may occur more efficiently at higher temperature. The positive values of $\Delta S^{\circ}$ also shows the increment randomness at the surface of 
adsorbent during the adsorption process which can be reflected by the affinity of $\mathrm{GO}_{\mathrm{h}}$-Tpy for heavy metal ions and suggested some conformational changes in the $\mathrm{GO}_{\mathrm{h}}$-Tpy structure. On the other hand, the positive value of $\Delta \mathrm{H}^{\circ}$ indicates that the adsorption process for $\mathrm{GO}_{\mathrm{h}}$-Tpy is purely based on endothermic process. This result also supports the suggestion that the adsorption capacity of adsorbent increases with the temperature.

\section{Experimental}

\section{Reagents and Solutions}

Commercially available metal salts, organic compounds and solvents were purchased from Sigma Aldrich or/and Merck Chemical Company (analitycal grade), used without any purification. All solutions were prepared with Mili-Q deionized water. 4-([2,2':6',2'terpyridin]-4'-yloxy)butan-1-amine (Tpy) was synthesized according to synthetic route described in detail in Supporting Information (see Experimental section and Fig. S1).

\section{Synthesis of $\mathrm{GO}$ and $\mathrm{GO}_{\mathrm{h}}$}

The GOs with different oxidation degrees were synthesized by using modified Hummers method (see Experimental section in $\mathrm{SI}$ for further information) according to previously published work..$^{80} \mathrm{GO}$ is generally prepared as stable aqueous dispersion at $4 \mathrm{mg} \mathrm{mL}^{-1}$ concentration by treating graphite with the appropriate mass of $\mathrm{KMnO}_{4}$ in $\mathrm{H}_{2} \mathrm{SO}_{4}$. The different graphite: $\mathrm{KMnO}_{4}$ ratio introduces various quantities of oxygen atoms on the surface $\mathrm{GO}$ in the form of epoxy, hydroxyl and carboxyl groups. Functional groups containing oxygen atoms exhibit an ability to form stable dative bonds with chosen heavy metal ions. We decided to use two different graphite: $\mathrm{KMnO}_{4}$ ratios (1:1.5 and 1:3 w:w) yielding GO with $39.8 \%$ and $58.8 \%$ oxidation degrees, respectively. The composition of $\mathrm{GO}$ and $\mathrm{GO}_{\mathrm{h}}$, which were subsequently used for the synthesis of hybrids, were characterized by various experimental techniques including XPS (see SI for further information).

\section{Preparation of GO-Tpy and $\mathrm{GO}_{\mathrm{h}}$-Tpy}

A batch of GO-Tpy and $\mathrm{GO}_{\mathrm{h}}$-Tpy were prepared as follows: a mixture of ethanol $(100 \mathrm{~mL})$ and $\mathrm{GO}$ or $\mathrm{GO}_{\mathrm{h}}\left(100 \mathrm{~mL}, 4 \mathrm{mg} \mathrm{mL}^{-1}\right)$ was sonicated for $30 \mathrm{~min}$ and then $100 \mathrm{~mL}$ of previously optimized 2-fold excess of Tpy in ethanol ( $8 \mathrm{mg} \mathrm{mL}^{-1}$ ) was added. The mixture was vigorously stirred overnight under reflux. The resulting powder was then filtered and washed several times with water/ethanol mixture (1:1 vol:vol). Finally, Soxhlet extraction was used to remove unreacted residuals. The resulting black powder was then freeze-dried for $24 \mathrm{~h}$ under vacuum. Preparation of the new hybrids was controlled during the synthesis via XPS and elementary analysis (see table S2-3) and its detailed characterization is described in the main text.

\section{Instruments}

The morphology of GO, $\mathrm{GO}_{\mathrm{h}}$, GO-Tpy and $\mathrm{GO}_{\mathrm{h}}$-Tpy was analysed by scanning electron microscopy (SEM) using a FEI Quanta 250 FEG instrument. SEM samples were prepared by mounted on carbon conductive tabs followed by gold coating. The composition of GOs as well as GO-based hybrids were characterized with a Thermo Scientific KAlpha $x$-ray photoelectron spectrometer. The measurements were performed using basic chamber pressure of $\sim 10^{-9} \mathrm{mbar}$ and an $\mathrm{Al}$ anode as the $\mathrm{X}$-ray source (X-ray radiation of $1486 \mathrm{eV})$. Spot sizes of $400 \mu \mathrm{m}$ were used and pass energies of 200.00 $\mathrm{eV}$ for wide energy scans (10 scans) and 10.00-20.00 eV for highresolution scans (20 scans) were exploited. The $\sim 5 \mathrm{mg}$ of $\mathrm{GO}, \mathrm{GO}_{\mathrm{h}}$, GO-Tpy and $\mathrm{GO}_{\mathrm{h}}$-Tpy samples are attached to copper film as powder. The $\mathrm{C} 1 \mathrm{~s}$ photoelectron binding energy was set at $284.5 \pm 0.2 \mathrm{eV}$ and used as a reference for calibrating the other peak positions. For each sample, the analysis was repeated three times. Fourier transform infrared (FTIR) spectra were recorded within the mid-IR range $\left(500-4000 \mathrm{~cm}^{-1}\right)$ by using a Perkin Elmer Spectrometer (Spectrum Two) equipped with ATR Diamond. The hybrid in the form of powder, earlier dried in a freeze dryer was studied at room temperature. The specific surface area was carried out on a Micromeritics ASAP 2050 surface area and porosity analyser. Prior to the Braunauer-EmmettTeller (BET) method, the samples were outgassed for 10 hours at 100 ${ }^{\circ} \mathrm{C}$. The specific surface area was determined from adsorption/desorption isotherms of nitrogen at $77 \mathrm{~K}$ and pressures up to 1 bar. The zeta potential was measured at various $\mathrm{pH}$ by Malvern Zetasizer Nano ZS instrument at room temperature. Thermogravimetric analysis (TGA) were carried out in the temperature range $50-500{ }^{\circ} \mathrm{C}$ operating under ambient condition, with a ramp of $10{ }^{\circ} \mathrm{C} / \mathrm{min}$ on a Mettler Toledo TGA/SDTA851e system. Raman spectra were measured at room temperature by Renishaw microscope with a 100x objective, laser excitation wavelength of $532 \mathrm{~nm}$ and laser power of $0.05 \%$. The silicon peak at $520.3 \mathrm{~cm}^{-1}$ was took as reference for wavenumber calibration. The $D$ and $G$ peaks were fitted with combined Gaussian and Lorentzian functions. X-ray powder diffraction (XRD) data were collected on powder specimens using Bruker ASX D8 Advanced equipped with $\mathrm{Cu}$ anode with $\mathrm{K} \alpha$ radiation $(\lambda=1.5418 \AA$ ) . Diffraction patterns were collected at room temperature in the scattered angular range between $6^{\circ}$ and $30^{\circ}$ with an angular resolution of $0.02^{\circ}$ per step and a typical counting time 4 of $10 \mathrm{~s}$ per step. Nuclear magnetic resonance $\left({ }^{1} \mathrm{H}\right.$ NMR) were recorded on a Mercury-plus-300 $\mathrm{MHz}$ spectrometer and calibrated against the residual protonated solvent signals $\left(\mathrm{CDCl}_{3}\right.$ : $\left.\delta=7.26\right)$, given in $p p m$. Elemental analyses were performed by Perkin Elmer 2400II. The concentration of metal ions was determined using flame atomic absorption spectrometry (F-AAS) with deuterium arc background correction, equipped with a hollow cathode lamp. An air-acetylene burner was used. The wavelengths (spectral band pass) were $213.86 \mathrm{~nm}, 230.79 \mathrm{~nm}$ and $231.60 \mathrm{~nm}$ for $\mathrm{Zn}(\mathrm{II}), \mathrm{Ni}(\mathrm{II})$ and $\mathrm{Co}(\mathrm{II})$, respectively. The nebulizer flow rate was set to $5.0 \mathrm{~mL} \mathrm{~min}^{-1}$.

\section{Conclusions}

In summary, we have reported the synthesis of a novel 3D $\mathrm{GO}_{\mathrm{h}}{ }^{-}$ Tpy hybrid by means of a facile and effective covalent bond formation. Compared to the as-prepared $\mathrm{GO}, \mathrm{GO}_{\mathrm{h}}$ and GO-Tpy, the $\mathrm{GO}_{\mathrm{h}}$-Tpy adsorbent exhibited the highest adsorption efficiency of heavy metal ions due to synergist contribution of $\mathrm{GO}_{\mathrm{h}}$ and Tpy components. The maximum adsorption capacities $\left(q_{\max }\right)$ of $\mathrm{GO}_{\mathrm{h}}$-Tpy system fitted by Langmuir isotherm model for $\mathrm{Ni}(\mathrm{II}), \mathrm{Zn}(\mathrm{II})$ and $\mathrm{Co}(\mathrm{II})$ are achieved at $\mathrm{pH}=6$ reaching 462,421 and $336 \mathrm{mg} \mathrm{g}^{-1}$, respectively, being the highest reported values in the literature including pristine GO and GO-based sorbents. The adsorption of $\mathrm{Ni}(\mathrm{II}), \mathrm{Zn}(\mathrm{II})$ and $\mathrm{Co}(\mathrm{II})$ was described well 
using the pseudo-second-order kinetic model, indicating that the process is driven by strong complexation of metal ions with the oxygen $\left(\mathrm{GO}_{h}\right)$ and nitrogen (Tpy) atoms present in the hybride. $\mathrm{GO}_{\mathrm{h}}$-Tpy exhibits outstanding remediation performance towards heavy metal ions (Ni(II), Zn(II), Co(II)), attributed to its high surface-to-volume ratio and interconnected pore network in the 3D architecture. Specifically, a selective sorption of alkali and alkaline metal ions from the drinking water samples was demonstrated, followed by desirable cycling stability, reusability and ease of separation operation of the $\mathrm{GO}_{\mathrm{h}}$-Tpy hybrid, paving the way towards application of this type of adsorbents in real-life wastewater purification processes.

\section{Conflicts of interest}

The authors declare no competing financial interest.

\section{Acknowledgements}

This work was supported by the National Science Centre (Grant no. 2017/27/N/ST5/00173) D.P acknowledges the support from the Embassy of France in Poland in the form of scholarship at the Institut de Science et d'Ingénierie Supramoléculaires, University of Strasbourg. Additionally, D.P. acknowledge the support from Foundation for Polish Science (FNP) in the form of scholarship. A.G. Foundation for Polish Science (FNP) in the form of scholarship is gratefully acknowledged. Y.N. acknowledge JSPS KAKENHI (2OH05224) for finantial support. We also acknowledge funding from European Commission through the ERC Proof-of-Concept project GRAPHEME (GA899596), the Graphene Flagship Core 3 project (GA-881603), the Agence Nationale de la Recherche through the Labex project CSC (ANR-10-LABX-0026 CSC) within the Investissement d'Avenir program (ANR-10-120 IDEX-0002-02), the International Center for Frontier Research in Chemistry (icFRC) as well as the Institut Universitaire de France (IUF).

\section{References}

1. J. B. Zimmerman, P. T. Anastas, H. C. Erythropel and W. Leitner, Science, 2020, 367, 397-400.

M. Z. Jacobson, Energy Environ. Sci., 2009, 2, 148-173.

F. Fu and Q. Wang, J. Environ. Manage., 2011, 92, 407-418.

R. P. Schwarzenbach, T. Egli, T. B. Hofstetter, U. v. Gunten and B. Wehrli, Annu. Rev. Environ. Resour., 2010, 35, 109-136.

B. Dhal, H. N. Thatoi, N. N. Das and B. D. Pandey, J. Hazard. Mater., 2013, 250-251, 272-291.

N. Rascio and F. Navari-Izzo, Plant Science, 2011, 180, 169-181.

P. C. Nagajyoti, K. D. Lee and T. V. M. Sreekanth, Environ. Chem. Lett., 2010, 8, 199-216.

L. Järup, Br. Med. Bull. , 2003, 68, 167-182.

P. B. Tchounwou, C. G. Yedjou, A. K. Patlolla and D. J. Sutton, in Molecular Clinical and Environmental Toxicology, ed. A. Luch, Springer Basel, Basel, 2012, pp. 133-164.

10. N. Zhang, W. Qi, L. Huang, E. Jiang, J. Bao, X. Zhang, B. An and G. He, Chin. J. Chem. Eng., 2019, 27, 1348-1360.

J. Park, P. Bazylewski and G. Fanchini, Nanoscale, 2016, 8, 9563-9571.

S. Wadhawan, A. Jain, J. Nayyar and S. K. Mehta, J. Water Process. Eng., 2020, 33, 101038.

13. X. Liu, R. Ma, X. Wang, Y. Ma, Y. Yang, L. Zhuang, S. Zhang, R. Jehan, J. Chen and X. Wang, Environ. Pollut., 2019, 252, 62-73.
S. Remanan, N. Padmavathy, S. Ghosh, S. Mondal, S. Bose and N. C. Das, Sep. Purif. Rev., 2020, 1-21.

S. Babel and T. A. Kurniawan, J. Hazard. Mater., 2003, 97, 219-243.

T. Kouznetsova, A. Ivanets, V. Prozorovich, A. Hosseini-Bandegharaei, H. N. Tran, V. Srivastava and M. Sillanpää, Wat. Sci. Technol., 2020, 82, 984-997. A. Alsbaiee, B. J. Smith, L. Xiao, Y. Ling, D. E. Helbling and W. R. Dichtel, Nature, 2016, 529, 190-194.

Z. Reddad, C. Gerente, Y. Andres and P. L. Cloirec, Environ. Technol., 2003, 24, 257-264.

S. Milićević, V. Milošević, D. Povrenović, J. Stojanović, S. Martinović and B. Babić, Clays Clay Miner., 2013, 61, 508-516.

G. Crini, Bioresour. Technol., 2006, 97, 1061-1085.

X. Qu, P. J. J. Alvarez and Q. Li, Water Res., 2013, 47, 3931-3946.

H. N. Tran, H. C. Nguyen, S. H. Woo, T. V. Nguyen, S. Vigneswaran, A. Hosseini-Bandegharaei, J. Rinklebe, A. Kumar Sarmah, A. Ivanets, G. L. Dotto, T. T. Bui, R.-S. Juang and H.-P. Chao, Crit. Rev. Env. Sci. Tec. , 2019, 49, 2155-2219.

H. N. Tran and H.-P. Chao, Environ. Sci. Pollut. Res., 2018, 25, 12808-12820. S. Yang, J. Li, D. Shao, J. Hu and X. Wang, Journal of Hazardous Materials, 2009, 166, 109-116.

C. Xu, C. Jiao, R. Yao, A. Lin and W. Jiao, Environ. Pollut., 2018, 233, 194200.

Z. Lin, Y. Hu, Y. Yuan, B. Hu and B. Wang, Ecotoxicol. Environ. Saf., 2021, 208, 111451.

X. Liu, H. Pang, X. Liu, Q. Li, N. Zhang, L. Mao, M. Qiu, B. Hu, H. Yang and X. Wang, The Innovation, 2021, 2, 100076.

S. Chowdhury and R. Balasubramanian, Adv. Colloid Interface Sci., 2014, 204, 35-56.

F. Perreault, A. Fonseca de Faria and M. Elimelech, Chem. Soc. Rev., 2015, 44, 5861-5896.

S. C. Smith and D. F. Rodrigues, Carbon, 2015, 91, 122-143.

I. Ali, A. A. Basheer, X. Y. Mbianda, A. Burakov, E. Galunin, I. Burakova, E. Mkrtchyan, A. Tkachev and V. Grachev, Environ. Int., 2019, 127, 160-180. D. H. Seo, S. Pineda, Y. C. Woo, M. Xie, A. T. Murdock, E. Y. M. Ang, Y. Jiao, M. J. Park, S. I. Lim, M. Lawn, F. F. Borghi, Z. J. Han, S. Gray, G. Millar, A. Du, H. K. Shon, T. Y. Ng and K. Ostrikov, Nta. Commun., 2018, 9, 683. G. Bottari, M. Á. Herranz, L. Wibmer, M. Volland, L. Rodríguez-Pérez, D. M. Guldi, A. Hirsch, N. Martín, F. D'Souza and T. Torres, Chem. Soc. Rev., 2017, 46, 4464-4500.

S. Navalón, J. R. Herance, M. Álvaro and H. García, Chem. Eur. J., 2017, 23, 15244-15275.

P. Samaddar, Y.-S. Son, D. C. W. Tsang, K.-H. Kim and S. Kumar, Coord. Chem. Rev., 2018, 368, 93-114.

W. Peng, H. Li, Y. Liu and S. Song, J. Mol. Liq., 2017, 230, 496-504. S. Yang, C. Chen, Y. Chen, J. Li, D. Wang, X. Wang and W. Hu, ChemPlusChem, 2015, 80, 480-484.

R. Zare-Dorabei, S. M. Ferdowsi, A. Barzin and A. Tadjarodi, Ultrason Sonochem., 2016, 32, 265-276.

G. Sheng, C. Huang, G. Chen, J. Sheng, X. Ren, B. Hu, J. Ma, X. Wang, Y. Huang, A. Alsaedi and T. Hayat, Environ. Pollut., 2018, 233, 125-131.

R. Sitko, E. Turek, B. Zawisza, E. Malicka, E. Talik, J. Heimann, A. Gagor, B. Feist and R. Wrzalik, Dalton Trans., 2013, 42, 5682-5689.

M. Ramezanzadeh, M. Asghari, B. Ramezanzadeh and G. Bahlakeh, Chem. Eng. J., 2018, 337, 385-397.

L. P. Lingamdinne, J. R. Koduru, H. Roh, Y.-L. Choi, Y.-Y. Chang and J.-K. Yang, Hydrometallurgy, 2016, 165, 90-96.

F. Fang, L. Kong, J. Huang, S. Wu, K. Zhang, X. Wang, B. Sun, Z. Jin, J. Wang, X.-J. Huang and J. Liu, J. Hazard. Mater., 2014, 270, 1-10.

C. Zolezzi, C. F. Ihle, C. Angulo, P. Palma and H. Palza, Ind. Eng. Chem. Res., 2018, 57, 15722-15730.

M. M. Kadam, O. R. Lokare, K. V. M. K. Kireeti, V. G. Gaikar and N. Jha, RSC Adv., 2014, 4, 62737-62745.

A. Dąbrowski, Adv. Colloid Interface Sci., 2001, 93, 135-224.

R. D. Hancock, Chemical Society Reviews, 2013, 42, 1500-1524.

A. Gorczyński, J. M. Harrowfield, V. Patroniak and A. R. Stefankiewicz, Chemical Reviews, 2016, 116, 14620-14674.

S. Chakraborty and G. R. Newkome, Chem. Soc. Rev., 2018, 47, 3991-4016. H. Hofmeier and U. S. Schubert, Chem. Soc. Rev., 2004, 33, 373-399. J. Ding, H. Zhao, Z. Shao and H. Yu, ACS Appl. Mater. Interfaces, 2019, 11, 42646-42653.

D. Zhou, Q.-Y. Cheng, Y. Cui, T. Wang, X. Li and B.-H. Han, Carbon, 2014, 66, 592-598.

S. Song, Y. Xue, L. Feng, H. Elbatal, P. Wang, C. N. Moorefield, G. R. Newkome and L. Dai, Angew. Chem. Int. Ed., 2014, 53, 1415-1419. X. Zhou, T. Zhang, C. W. Abney, Z. Li and W. Lin, ACS Appl. Mater. Interfaces, 2014, 6, 18475-18479.

T. Szabó, T. Szabó-Plánka, D. Jónás, N. V. Nagy, A. Rockenbauer and I. Dékány, Carbon, 2014, 72, 425-428.

Y. Chen, X. Zhang, D. Zhang, P. Yu and Y. Ma, Carbon, 2011, 49, 573-580. 
57. D. Zhao, X. Gao, C. Wu, R. Xie, S. Feng and C. Chen, Appl. Surf. Sci., 2016 384, 1-9.

58. A. C. Ferrari and D. M. Basko, Nat. Nanotech., 2013, 8, 235-246.

59. J. Liu, X. Ge, X. Ye, G. Wang, H. Zhang, H. Zhou, Y. Zhang and H. Zhao, J. Mat. Chem. A, 2016, 4, 1970-1979.

60. X. Dong, X. Wang, J. Wang, H. Song, X. Li, L. Wang, M. B. Chan-Park, C. M. Li and P. Chen, Carbon, 2012, 50, 4865-4870.

61. X. Zhang, A. Ciesielski, F. Richard, P. Chen, E. A. Prasetyanto, L. De Cola and P. Samorì, Small, 2016, 12, 1044-1052.

62. A. Calborean, F. Martin, D. Marconi, R. Turcu, I. E. Kacso, L. Buimagalarinca, F. Graur and I. Turcu, Mater. Sci. Eng., 2015, 57, 171-180.

63. F. Zhao, E. Repo, Y. Song, D. Yin, S. B. Hammouda, L. Chen, S. Kalliola, J. Tang, K. C. Tam and M. Sillanpää, Green Chem., 2017, 19, 4816-4828.

64. F. A. Martin, D. Marconi, S. Neamtu, T. Radu, M. Florescu, R. Turcu, C. Lar, N. D. Hădade, I. Grosu and I. Turcu, Mater. Sci. Eng. C, 2017, 75, 13431350.

65. H. X. Zhong, J. Wang, Y. W. Zhang, W. L. Xu, W. Xing, D. Xu, Y. F. Zhang and X. B. Zhang, Angew. Chem. Int. Ed., 2014, 53, 14235-14239.

66. R. Dash, J. Chmiola, G. Yushin, Y. Gogotsi, G. Laudisio, J. Singer, J. Fischer and S. Kucheyev, Carbon, 2006, 44, 2489-2497.

$67 . \quad$ B. Song, C. Sizemore, L. Li, X. Huang, Z. Lin, K.-s. Moon and C.-P. Wong, J. Mat. Chem. A, 2015, 3, 21789-21796.

68. Q. Fu, L. Zhang, H. Zhang, X. Chen, M. Li and M. Gong, Environ. Res., 2020, 186, 109608.

69. X. Zhang, Y. Huang, Y. Wang, Y. Ma, Z. Liu and Y. Chen, Carbon, 2009, 47, 334-337.

$70 . \quad$ R. D. Hancock, Chem. Soc. Rev., 2013, 42, 1500-1524.

71. C.-J. Shih, S. Lin, R. Sharma, M. S. Strano and D. Blankschtein, Langmuir, 2012, 28, 235-241.

72. J. M. Hamilton, M. J. Anhorn, K. A. Oscarson, J. H. Reibenspies and R. D. Hancock, Inorg. Chem., 2011, 50, 2764-2770.

73. L. Cui, Y. Wang, L. Gao, L. Hu, L. Yan, Q. Wei and B. Du, Chem. Eng. J., 2015, 281, 1-10.

R. D. Hancock and A. E. Martell, Chem. Rev., 1989, 89, 1875-1914.

B. H. Hameed, J. Hazard. Mater., 2008, 154, 204-212.

K. Thakur and B. Kandasubramanian, J. Chem. Eng. , 2019, 64, 833-867.

S. Figaro, J. P. Avril, F. Brouers, A. Ouensanga and S. Gaspard, J. Hazard. Mater., 2009, 161, 649-656.

78. X. Mi, G. Huang, W. Xie, W. Wang, Y. Liu and J. Gao, Carbon, 2012, 50, 4856-4864.

79. Y. Liu, Q. Zhao, G. Cheng and H. Xu, Chem. Eng. J., 2011, 173, 792-800.

80. N. Morimoto, T. Kubo and Y. Nishina, Sci. Rep. , 2016, 6, 21715. 